\title{
TÍTULO DE CRÉDITO: CONSEQUÊNCIAS JURÍDICAS APLICÁVEIS AO EMITENTE SUSTANTE DE CHEQUES PÓS-DATADOS
}

\author{
Humberto Pedrosa Santos, Rafaela Nayara Ferreira Rodrigues \\ Universidade do Oeste Paulista - UNOESTE, Curso de Direito, Presidente Prudente, SP. E-mail: \\ humbertopedrosa123@hotmail.com
}

\begin{abstract}
RESUMO
A presente pesquisa tem por finalidade refletir sobre o abuso do direito pelo emitente do cheque sustando-o ou revogando com intuito de enriquecimento indevido, verifica-se que a infundada sustação do pagamento do cheque tem os mesmos efeitos penais da emissão de cheque sem fundos, podendo configurar crime de estelionato conforme dispõe o artigo $171 \S 2$ ㅇ VI do código penal e ação monitoria conforme dispositivo de lei art.700 do NCPC. Assim para que a pesquisa transcorra adequadamente, adotou-se o método hipotético dedutivo realizado através de revisão bibliográfica, com a utilização de doutrina, jurisprudência, artigos eletrônicos, normas constitucionais e infraconstitucionais. Conclui-se que deve ser aplicado o Código penal nas relações de abuso de Direito praticado pelo emitente frente ao sacado.
\end{abstract}

Palavras chaves: Abuso do direito. Sanções. Cheque Pós-datado.

\section{CREDIT TITLE: CONSEQUENCES JURIDICAL APPLICABLE TO THE POST-DATED SUBSTANTIVE CHECKER}

\begin{abstract}
The following research has for its purpose to ponder about the abuse of the issuing's right of the check, withholding it or revoking it with the intention of undue enrichment, verifying that the unfounded withholding of the check's payment has the same penal effects of the emission of bad checks (checks with insuficiente funds), enabling to configure a stelionate crime according to the article 171, of the second paragraph of the penal code and monitored action as disposed on the law article 700 from NCPC. Therefore for the research to course through adequately, it assumed the hypothetical deductive method made of bibliographic revision, with the usage of doctrines, jurisprudence, electronic articles, constitucional and infraconstitucional norms. Concluding that the penal code must be applied on the relations of abuse of Law practiced by the issuing towards the payer.
\end{abstract}

Keywords: Law abuse, sanction, postdated check. 


\section{INTRODUÇÃO}

Nos dias atuais verifica-se que o comercio em geral vem enfrentando um problema que está se tornando muito comum, ou seja, a inadimplência, devido o aumento do desemprego no país e a queda do rendimento médio da população tem cada vez mais impulsionado o consumidor a não cumprir com suas obrigações, em praticamente todas as suas modalidades de relação consumerista, concernindo o uso excessivo de cheques pós-datado.

Para que a pesquisa se desenvolva de modo adequado é necessária à realização de um questionamento e posteriormente responde-lo: Existe a possibilidade de o emitente do cheque pós-datado sustar o cheque pela alínea 21 indevidamente para que se evite a negativação e inclusão no CCF (Cadastro de Emitentes de Cheques sem Fundos)? O que fazer?

O presente trabalho será desenvolvido a partir do estudo cauteloso dos princípios constitucionais explorando as teorias que definem o conceito de cheque pós-datado com ênfase na destrutibilidade, para posicionarmos, posteriormente diante do estudo, reflexionando assim sobre as divergências doutrinarias construída ao longo dos anos, entretanto esta pesquisa não esgota a possibilidade de futuros estudos.

\section{METODOLOGIA}

Será aplicado na elaboração dá pesquisa o método hipotético dedutivo, apoiando-se na edificação doutrinária, jurisprudencial e normativa, assim como pesquisa bibliográfica por meio uma ampla leitura de artigos científicos, doutrina e jurisprudência.

\section{TITULOS DE CRÉDITO: CHEQUE}

O cheque não é um título de credito tão recente como aparenta ser, em uma concepção histórica compreendemos que esse é o resultado de uma longa evolução, partindo da ausência de moeda, em virtude disso, realizava-se o escambo, ou seja, a simples troca de mercadorias sem a equivalência de valor.

Logo na Idade Média, surgiu o costume de confiar a guarda de valores com um ourives, individuo cuja profissão era de fabricante, vendedor e negociante de peças de ouro e prata. Esse como garantia principiou a emissão de papeis que na época representavam partidas de ouro que guardavam. Com o tempo tais papeis passaram a ser utilizados para efetuar pagamentos, circulando de mão em mão e dando origem a moeda de papel. No Brasil, a primeira referência ao cheque apareceu em 1845, quando se fundou o Banco Comercial da Bahia. Entretanto apenas em 1893, pela Lei 149-B, surgiu à primeira citação referente ao cheque, no seu artigo 16, letra "a".

Diante desses acontecimentos históricos, o tema é atualmente regulado pela Lei $\mathrm{n}$. 7.357/87 Lei do Cheque, que determina os parâmetros regulamentadores de padronização do cheque, necessários para que o mesmo passe a valer, previstos no artigo 10 e $2 \circ$ da emissão e da forma do cheque, Senão Vejamos:

Art. 10 O cheque contêm:

I - a denominação " cheque" inscrita no contexto do título e expressa na língua em que este é redigido;

II - a ordem incondicional de pagar quantia determinada;

III - o nome do banco ou da instituição financeira que deve pagar (sacado);

IV - a indicação do lugar de pagamento;

V - a indicação da data e do lugar de emissão;

VI - a assinatura do emitente (sacador), ou de seu mandatário com poderes especiais.

Parágrafo único - A assinatura do emitente ou a de seu mandatário com poderes especiais pode ser constituída, na forma de legislação específica, por chancela mecânica ou processo equivalente. 
Sendo instituída a Lei do cheque, que foi elaborada buscando segurança do cheque e padronização do mesmo. Nesse sentido o cheque é um título de credito emitido no papel oferecido pelo banco sacado.

De acordo com Coelho (2016, p.439), conceitua que "O cheque é ordem de pagamento à vista, emitida contra um banco, em razão de provisão que o emitente possui junto ao sacado, proveniente essa de contrato de depósito bancário ou de abertura de credito".

Assevera ainda, Coelho (2016, p.439) que: "O cheque é título de crédito de modelo vinculado, só podendo ser eficazmente emitido no papel fornecido pelo banco sacado (em talão ou avulso)".

Realizando um breve analise do conceito legal de títulos de credito, verifica-se que o cheque é uma modalidade de títulos, sendo uma ordem de pagamento geralmente à vista existindo, entretanto a possibilidade de ser pós-datado.

\section{CHEQUE PÓS-DATADO}

Conforme verificou-se anteriormente, o cheque tem se revelado no mercado nacional um instrumento extremamente ágil e apropriado à concessão de crédito a empresários e fornecedores de mercadorias e serviços.

Waldo Fazzio Junior leciona que:

O artigo 32 da Lei do Cheque e o art. 28 da Lei Uniforme (Decreto 57.595/66) vedam o cheque pós-datado, determinando que "o cheque apresentado para pagamento antes do dia indicado como data da emissão é pagável no dia da apresentação". Tratando-se de ordem de pagamento a vista, é irrelevante que se emita pré-datado, em garantia ou como promessa de pagamento, porque não perde a cambiaridade, nem a consequente executividade, o cheque emitido em garantia de dívida, ou o cheque a que falte a data de emissão ou pós-datado. "A emissão de cheque pós-datado, popularmente conhecido como cheque pré-datado, não o desnatura como título de crédito, e traz como única consequência a ampliação do prazo de apresentação. (FAZZIO JUNIOR, 2017, p.341).

Destarte, nota-se que o cheque pós-datado é um importante instrumento de concessão de crédito ao consumidor, embora o ato de emitir um cheque pós datado não produza efeitos perante o banco sacado, na hipótese de apresentação para liquidação, visto que este representa um acordo entre tomador e emitente, assim a apresentação precipitada do cheque significa o descumprimento do acordo.

\section{CONTRAORDEM E SUSTAÇÃO}

Fundamentou-se, essa teoria através do disposto no artigo 35 e 36 da Lei 7.357/85 que traz a seguinte redação:

Art. 350 emitente do cheque pagável no Brasil pode revogá-lo, mercê de contra-ordem dada por aviso epistolar, ou por via judicial ou extrajudicial, com as razões motivadoras do ato.

Parágrafo único - A revogação ou contra-ordem só produz efeito depois de expirado o prazo de apresentação e, não sendo promovida, pode o sacado pagar o cheque até que decorra o prazo de prescrição, nos termos do art. 59 desta Lei.; (BRASIL, 1985).

Art. 36 Mesmo durante o prazo de apresentação, o emitente e o portador legitimado podem fazer sustar o pagamento, manifestando ao sacado, por escrito, oposição fundada em relevante razão de direito.

$\S 1$ ㅇ A oposição do emitente e a revogação ou contra-ordem se excluem reciprocamente. § 2ㅇ Não cabe ao sacado julgar da relevância da razão invocada pelo oponente. (BRASIL, 1985).

A doutrina entende que o pagamento do cheque, poderá ser sustado pela alínea 21 pelo emitente em duas hipóteses: a) revogação, conhecida popularmente como contraordem (LC, 
art.35) e b) oposição (LC, art. 36). Em ambas, objetivo é impedir a liquidação do cheque, pelo banco sacado; pressupõem-se, portanto, que não tenha essa se realizado na data da sustação, sendo o cheque regularmente processado e pago, não pode ser objeto de revogação ou oposição.

Fundamentou-se, que consoante a Res. BC 3.972/11, as instituições financeiras devem exigir, para a efetivação de sustação ou revogação de cheque, uma solicitação formalizada pelo interessado, não cabendo julgamento sobre o mérito ou a relevância do motivo apresentado, admitido o emprego de transação ou comunicação eletrônica, mediante senha ou qualquer procedimento apto à produção de prova para fins legais.

Ressalta-se, "que ao banco sacado não cabe julgar a relevância dos motivos justificadores apresentados pelo interessado, no ato de sustação de cheque revogação ou oposição". (COELHO, 2016, p. 449).

Deste modo, constata-se a existência de duas modalidades distintas de sustação do cheque, a revogação ou contra-ordem e a oposição. A primeira (contra-ordem) é ato praticado exclusivamente pelo do emitente e somente tem vigência depois de expirado o prazo de apresentação. Já a oposição pode ser efetuada tanto pelo emitente quanto pelo beneficiário ou portador diferentemente da contraordem a oposição tem vigência imediata, assim, caso a instituição financeira recusar-se a acolher o pedido de sustação estará agindo ilegalmente, uma vez que tal limitação aplica-se exclusivamente a contra-ordem.

\section{DO ABUSO DO DIREITO PELO EMITENTE}

Inicialmente, é necessário esclarecer que nos dias atuais perpetua-se uma valorização social muito grande, nesse paradigma, a teoria do abuso do Direito materializado em nosso ordenamento jurídico, traz alguns debates sob qual regramento jurídico está o abuso do Direito.

Silvio Rodrigues expõe em sua obra conceito do abuso do direito:

$\mathrm{O}$ abuso de direito ocorre quando o agente, atuando dentro das prerrogativas que o ordenamento jurídico lhe concede, deixa de considerar a finalidade social do direito subjetivo e, ao utilizá-lo desconsiderada mente, causa dano a outrem. Aquele que exorbita no exercício de seu direito, causando prejuízo a outrem, pratica ato ilícito, ficando obrigado a reparar. Ele não viola os limites objetivos da lei, mas, embora Ihes obedeça, desvia-se dos fins sociais a que está se destina, do espírito que a norteia. (RODRIGUES, 2017, p. 44).

Neste modelo, o Superior Tribunal de Justiça vem entendendo ser adequado a aplicação, apreciando no caso em concreto a existência dos pressupostos para a caracterização de abuso de direito na sustação indevida de cheque pela alínea 21:

TJ-PE - Apelação APL 3227327 PE (TJ-PE) Data de publicação: 20/01/2014 Ementa: APELAÇÃO CÍVEL. DIREITO CIVIL. CHEQUES INDEVIDAMENTE SUSTADOS. MÁ-FÉ DO APELADO. DANO MORAL EXISTENTE. APELO PROVIDO. No caso concreto, há o dever reparatório, à luz do disposto no art. 186 do CC, haja vista estar configurada a má-fé na atuação do Apelado que sustou os cheques emitidos sem comprovação de qualquer desacordo comercial com o Apelante; Inegáveis os transtornos decorrentes da ausência de crédito para compra de matéria-prima, os quais foram suportados pelo Apelante, com exclusividade, devido à sustação indevida dos cheques, situação para a qual não colaborou. Apelo provido, para condenar o Apelado ao pagamento de dano moral, arbitrado em R\$3.000,00 (três mil reais), corrigidos pela tabela do ENCOGE desde o arbitramento e acrescido de juros moratórios de $1 \%$ (um por cento) ao mês, a partir da data da citação, mantida a sentença em todos os seus demais termos. Encontrado em: EMENTA: APELAÇÃO CÍVEL. DIREITO CIVIL. CHEQUES INDEVIDAMENTE SUSTADOS. MÁ-FÉ DO APELADO. DANO MORAL... do CC, haja vista estar configurada a má-fé na atuação do Apelado que sustou os cheques emitidos..., com exclusividade, devido à sustação indevida dos cheques, situação para a qual não colaborou. - Apelo[...]. (BRASIL, 2014, p.1). 
Deste modo, constata-se que esta situação está se tornando cada vez mais comum, ou seja, a sustação de cheques de forma indevida, até mesmo fraudulenta, que acaba salvaguardando o mal pagador.

\section{CONSIDERAÇÕES FINAIS}

Ante todo exposto, conclui-se que a possibilidade de se revogar, assim como a própria oposição do cheque, tem se mostrado um escudo protetor ao mal pagador, que através da sustação do título, evita a inclusão de seu nome no Cadastro de Cheques sem Fundos (CCF) do Banco Central, e que em curto prazo o desobriga de pagar o que é devido ao sacado ou portador do título de credito sustado até que o mesmo acesse o judiciário.

Constata-se que, a hipótese aludida não exclui, de maneira automática, a responsabilidade Penal e Civil.

Entretanto, a redação da Lei n. 7.357/87 Lei do Cheque e Res. BC 3.972/11, não fornece uma proteção completa ao sacado e ao portador de boa-fé que.

Deste modo, Mostra-se possível e viável que ao analisar o caso em concreto onde figure o abuso de direito pelo emitente que fique constatada sua má-fé, que seja convertida de uma são civil para um processo criminal, devido a caracterização do crime de estelionato previsto no artigo 171 do Código Penal, garantido assim que diminua a quantidade de sustação de cheques pósdatados de forma desregrada.

\section{REFERÊNCIAS}

BRASIL, Banco Central do. Origem e evolução do dinheiro. Texto extraído da revista: "As Muitas Faces da Moeda" do Centro Cultural do Banco do Brasil. Disponível em <http://www.bcb.gov.br/htms/origevol.asp>. Acesso em 03 Ago. 2018.

BRASIL, Banco Central do. Resolução no 3.972. Promulgada em 28 de abril de 2011. Disponível em $<$

https://www.bcb.gov.br/pre/normativos/busca/normativo.asp?tipo=res\&ano=2011\&numero=397 2 >. Acesso em 06 Ago. 2018.

BRASIL, República Federativa do. Da emissão e da forma do cheque. Promulgada em 2 de setembro de 1985. Disponível em <http://www.planalto.gov.br/ccivil_03/leis//7357.htm>. Acesso em 05 Ago. 2018.

BRASIL. Superior Tribunal de Justiça. 2a Câmara Civil. Apelação no 3227327. Relator: Cândido José da Fonte Saraiva de Moraes, 20 de janeiro de 2014. Disponível em: < https://tjpe.jusbrasil.com.br/jurisprudencia/159615554/apelacao-apl-3227327-pe>. Acesso em: 06 ago. 2018.

COELHO, Fábio Ulhoa. Curso de direito comercial. 20 ed. São Paulo: Revista dos Tribunais. 2016, p. 439-454.

JUNIOR, Waldo Fazzio. Manual de direito comercial. 18 ed. São Paulo: Atlas, 2017.

MAGALHÃES, Aldeci de Aquino. Natureza jurídica do cheque pós-datado. Âmbito Jurídico. Disponível em: <http://www.ambitojuridico.com.br/site/index.php?n_link=revista_artigos_leitura\&artigo_id=165 3>. Acesso em 05 Ago. 2018. 
RODRIGUES, Silvio. Direito civil. vol. 4, 20 ed. São Paulo: Saraiva. 2007, p. 45. 